\title{
The 5th International Conference on Gold Science, Technology and its Applications
}

University of Heidelberg, Germany Sunday 26 - Wednesday 29 July 2009

\section{Invited speakers}

\begin{abstract}
- 000 Venue
With its glorious natural setting, a wonderful castle, historic old town and a beautiful river set in the midst of rolling hills, Heidelberg is regarded as one of the most attractive cities in Germany. It is also a progressive city of international importance in the fields of science, research and business. Not only is Germany's oldest university based in Heidelberg (the venue for the conference), but so are a number of outstanding research institutions and industrial companies. It is a truly wonderful setting for GOLD 2009 and we look forward to welcoming you to see for yourself!
\end{abstract}

\section{$-\infty 00$ Key dates}

Notification of acceptance 2 April 2009

Final programme announced 15 April 2009

Conference

26-29 July 2009

Abstracts for posters can be submitted via the website up to the start of GOLD 2009.

\section{- 00 Students}

Special student rates for conference attendance have been announced on the conference website.
The Organisers are pleased to announce the following invited speakers for GOLD 2009 confirmed to date.

\section{Opening plenary presentations}

The conference will begin on Sunday afternoon, 26th July, with three plenary presentations:

- Peter Kondos, Barrick Gold, Overview of gold mining and extraction and current issues (title tbc)

- Christian Hagelüken, Umicore, Recycling of gold from electronics (title tbc)

- Christiane Eluère, Musée De France, Ancient Gold of Continental Europe

\section{Main conference sessions}

Plenary presentations

- Richard Puddephatt, University of Western Ontario, Molecular engineering in gold chemistry: From molecules to polymers and network materials

- Paul Mulvaney, University of Melbourne, Single gold nanocrystal spectroscopy - Steps towards active plasmonics

- Pietro Cavalotti, Politechnico Milano, The art and future of gold electroplating

- Wayne Goodman, Texas A \& M University, (title tbc)

- Masatake Haruta, Tokyo Metropolitan University, A New Frontier in Heterogeneous Catalysis: Gold Clusters

- Dean Toste, UC Berkeley ( $t b c)$

- Graham Hutchings, Cardiff University, Nanocrystalline gold catalysts for selective chemical synthesis

\section{Keynote presentations}

- Luigi Messori, University of Florence (Gold cytotoxicity)

- Mohammad Omary, University of North Texas (Gold luminescence)

- Konrad Seppelt, University of Berlin, Gold Fluorides and their role in MetalXenon Compounds

- Boonrat Lohwangwatana, Chulalongkorn University, Design and Synthesis of Gold Metallic Glass and its Applications

- Tobias Müller, W. C. Heraeus GmbH, Gold wire bonding in microelectronics an overview

- Brahim Lounis, Université Bordeaux, Optical detection of individual gold nanoparticles

- Ulrich Heiz, Technische Universität München, Catalysis of Gold: Each atom counts!

- Didier Astruc, Université Bordeaux, Interplay between Gold Nanoparticles and Dendrimers

- Vincent Rotello, University of Massachusetts, Gold Nanoparticles as Diagnostics and Therapeutics

- Mikael Käll, Chalmers University of Technology, SPR goes nano : using gold nanostructures for efficient refractive index sensing

- Avelino Corma, Universidad Politécnica de Valencia, Gold (III)-Metal organic frameworks for bridging the gap between homogeneous and heterogeneous gold catalysts

\section{Sponsors}

\section{-BASF}

The Chemical Company BASF Group

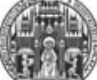

WORLD GOLD COUNCIL The University of Heidelberg

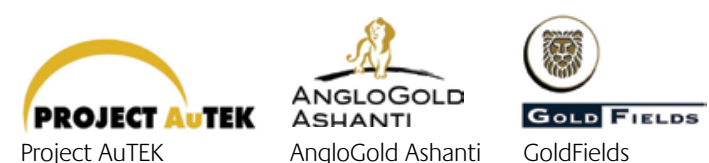

Heraeus

W. C. Heraeus $\mathrm{GmbH}$
METALOR

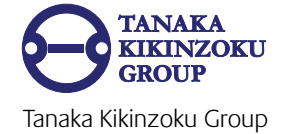

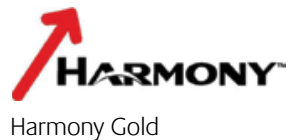

